\title{
Literature Review of Outdoor Physical Environment Design of Green Campus
}

\author{
Chongjie Wang ${ }^{1 *}$, Jie Li ${ }^{1}$, Hongmei Yin², Tao Fang ${ }^{1}$ and Qiang Chen ${ }^{3}$ \\ ${ }^{1}$ School of Architecture and Urban Planning, Shandong Jianzhu University, Jinan, China \\ ${ }^{2}$ Shandong Co-Innovation of Green Building, Jinan, China \\ ${ }^{3}$ School of Innovation and Entrepreneurship, Shandong Yingcai College, Jinan, China \\ *Corresponding author
}

\begin{abstract}
After reviewing the relevant literature on green campus, this study has analyzed the current design practice. It shows that there are shortcomings in the green campus design strategies for the outdoor physical environment. There are three aspects in the shortcomings: (1) the site planning, (2) the layout of buildings and micro-climate, and (3) the outdoor landscape and environment. This study recommends the following method be implemented so as to improve the design of the green campus outdoor physical environment. There are three parts in the method. First, the landscape system planning is the priority, that is to say, it is the terrain and hydrology and not the traditional man-made space forms that govern the planning structure and the overall plan. Second, use a computer simulation software set to optimize the layout of the buildings. Third, optimize the design of the walking space around the buildings so as to make the users feel more comfortable.
\end{abstract}

Keywords-green campus; outdoor physical environment; design strategies

\section{INTRODUCTION}

In 1995, the National Environmental Popularization and Education Work Outline initiated the concept of "green school" in China, and it was implemented between 1996 and 2010. In 2007, Tongji University played a demonstration role of a conservation-oriented campus in China. The technical guideline for the construction and management of the conservation-oriented campus was promulgated and implemented in 2009. In April 2013, the Evaluation Standard for Green Campus (CSUSGBC 04-2013) was implemented, which promoted the development of green campuses in China. The outdoor physical environment of the green campus has direct impacts on all the outdoor activities, which also affects the quality of the indoor environment. If the planning and design of the campus are already done, then there is little possibility of optimizing the physical environment. Further, the cost is high to achieve the same level of outdoor environment. Therefore, the outdoor physical environment design must start from the beginning of the campus planning stage. The site planning of a green campus affects the campus landscape system and the layout of the buildings directly. The layout of the buildings is an important factor of the outdoor microclimate, which directly affects the sunshine, wind, and so on. The walking space around the buildings is the most active areas for human activities. Hence, in the design, it must take its effect on the people in account.
In view of this, this paper focuses on the design of the outdoor physical environment of the green campus. The shortcomings in the present design in three aspects are highlighted: (1) the site planning, (2) the layout of buildings and micro-climate, and (3) the outdoor landscape and environment. Based on the review, this paper proposes design strategies for the outdoor physical environment.

\section{CONCEPT OF GREEN CAMPUS AND RESEARCH SCOPE}

The Evaluation Standard for Green Campus (CSUSGBC 04-2013) defines a green campus as a campus which is in harmony with its natural environment. During its service life, it maximizes the conservation of the resources, such as energy, water, materials and land. It also protects the environment and reduces pollution thereby providing a healthy teaching, applicable and efficient environment for the teachers and students. Professor Hong-wei Tan, Secretary General of China Green University Network, developed a radar map, as shown in Figure 1. It shows that a healthy environment, green planning and environmental conservation are important components in the development of a green campus.

The diversity of campus functions determines the complexity of its spatial layout. A green campus is also a park. It includes green planning, green buildings and green landscape, of which the green buildings have to be certified according to the Assessment Standard for Green Building (GB/T503782014). Further, the campus can be divided into indoor and outdoor environments. For each environment, there are physical and cultural environments. The scope of this paper is focused on the outdoor physical environment, as shown in Figure 2.

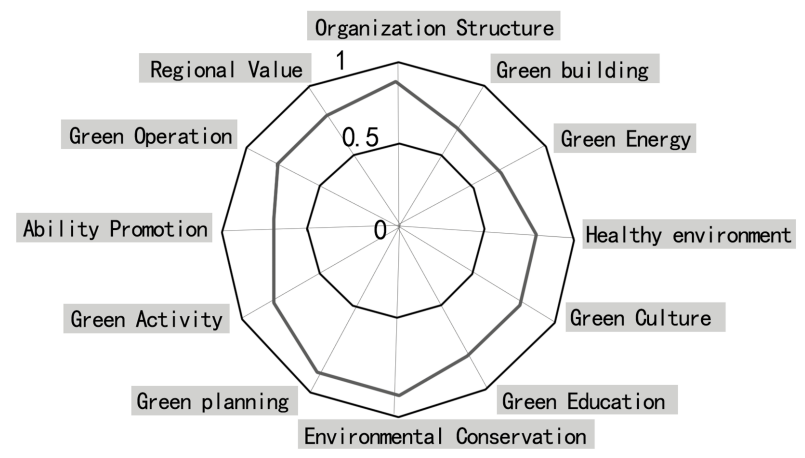

FIGURE I. SYSTEM 


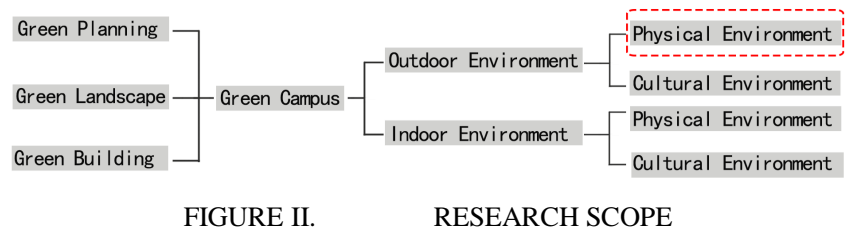

\section{CURRENT STUDY AND SHORTCOMINGS OF CAMPUS OUTDOOR PHYSICAL ENVIRONMENT}

The green campus is an integration of green planning, green buildings and green landscape. These three components correspond to the site, the micro-climate and the walking space, respectively. With respect to the three components, the following is a review of the green campus outdoor physical environment design strategies.

\section{A. Site Planning}

Professor Tie-mao Shi highlights that for the site planning of a green campus, the ecological planning of buildings and landscape should be included. He emphasizes the need to merge the biological nature and the society's culture in accordance to the construction practice of Shenyang Jianzhu University. He further emphasizes the importance of understanding the characteristics of natural resources and natural environment before the overall planning of the campus area, so as to make full use of the existing natural environment. Professor Chong-jie Wang led the construction of Shandong Jianzhu University from the site selection, and developed a plan for design according to the local conditions, which include a stone factory with a gully, a pit, and the Xue-shan hill. With these conditions, it was difficult to build the campus, but through the ingenious incorporation of the natural terrain, the project was successfully completed without removing any earth from the site. During the development of the Meixihu middle school in Hunan province, Professor Biao Hu advised a reasonable utilization of the underground space, according to the topography and landscape. His advice was good for the buildings layout, because it reduced the quantity of earthwork that was removed from the site.

From the green planning perspective, the three mentioned cases are for specific campuses, and they are located in different climatic regions. Shengyang Jianzhu University is in the severe cold region. Shandong Jianzhu University in is the cold region, and Mei-xi-hu middle school is in the hot-summer and cold-winter region. While the three campuses have been operating well, general planning design methods for a campus were not developed.

\section{B. Layout of Buildings and Outdoor Micro-climate}

The template is used to format your paper and style the text. All margins, column widths, line spaces, and text fonts are prescribed; please do not alter them. You may note peculiarities. For example, the head margin in this template measures proportionately more than is customary. This measurement and others are deliberate, using specifications that anticipate your paper as one part of the entire proceedings, and not as an independent document. Please do not revise any of the current designations.
Bao-xin $\mathrm{Li}$, hosting the designs of a university campus in Guangzhou City, and a middle school campus in Shaoyang, emphasized the design of a green campus should focus on the "wind" and "water" thereby achieving the "hiding of the wind" and the "inflowing of water". With such a design, the campus is in harmonious coexistence with nature. Using a computer simulation software Yu-kun Zhang has optimized the outdoor environment of Shijiazhuang Jingji University. Also using computer simulation, he has developed a planning and design method for green campuses. Yu Zhang has developed passive technologies for the enclosing form, path design, plane form, roof design and ventilation, which can determine the building height, depth, construction spacing and enclosure type. The use of a suitable enclosure type can reduce the negative effects of adverse weather in a severe cold region. Using the Southern Science and Technology University as an example, Peng Liu and Hong-wei Mao analyzed the landscape and physical environment digitally can thereby refining and quantifying the wind, sound, light, heat and other physical environmental factors of the campus. This analysis can improve the campus outdoor physical environment quality, and reduce costs. Guohua Tian recommended that the regional airflow constraints be taken into account in the overall planning of a campus and the layout of buildings. This is not only useful to the insulation and energy-saving of the buildings, but also to improve the summer and winter outdoor wind environments at the campus.

There are many studies on the layout of green campus and the design of outdoor physical environment. There is a consensus that the physical simulation software can be used to design the layout of the buildings and to optimize the outdoor physical environment. However, in practice, the green environment simulation analysis is only carried out after the conventional planning and architectural design are completed. Hence, the results of the simulation analysis and the optimal design are only for show and not used in the planning design, building groups design and landscape design. This planning and design process cannot be good for a green campus.

\section{Landscape and Environment}

Finally, complete content and organizational editing before formatting. Please take note of the following items when proofreading spelling and grammar:

Tie-mao Shi recommended that campus ecological landscape be integrated into the overall greening system. The greening system can be divided into two parts, i.e. the green space system, and the water system. In the design, it is recommended that the two parts be considered as a single system, thereby forming an ecological corridor. Guo-hua Tian considers the protection of the existing ecological environment around buildings is the primary method to improve the outdoor micro-climate. Only with this method, the wind around the buildings can be made to feel comfortable, and the plant can play the role of carbon fixation fully. Zhang Yu shows that by incorporating water, the waterfront treatment and water shape in the design, they can reduce the effects of the unfavorable climatic factors. Combining with the campus energy system, the water can play the role of temperature regulation in the cold region. By combining the designs of the landscape and the building groups, Bao-xin Li shows that using the computer simulation technology can achieve ecological rainwater 
management. Concave green grass, rain garden landscape can solve the problem of rainwater utilization and excretion. Using the landscape planning of Tianjin University as an example, Yu Hao and Lei Cao have developed a low impact development strategy in the green campus landscape design. The landscape design based on the principle of landscape ecology can control the runoff of rainfall from the source.

The campus landscape design practices are based on the completed campus planning, whose start and end points are not at the macro level, namely, not from the source. Although $\mathrm{Yu}$ Hao recommended that the source of rainfall at the site be controlled so as to achieve low impact development, it was not carried out at the initial stage of the campus planning. Therefore, these landscape designs cannot optimize the outdoor physical environment at all.

\section{SugGestions ACCORDING TO THE ABOVE STUDY}

The outdoor physical environment of a campus is closely related to its geographical location, terrain and hydrological condition. That is to say, the positives and the negatives of the green campus outdoor physical environment are already affected at the planning stage. In the preceding discussed campus outdoor physical environment design methods, there are three common characteristics. First, at the planning stage, the focus is on the space form for the land use, but there is no outdoor physical environment design. Second, the design is carried out before or concurrently with the simulation and optimization. Third, there is no design for the walking space around the buildings.

Hence, this study has developed a design method for the campus outdoor physical environment, which starts at the planning stage. There are three parts in the method. (1) The planning should start from the landscape system because the environment is governed by the existing landscape. Then, it makes rational use of the terrain topography, hydrological conditions, which forms the foundation for the subsequent planning and design. (2) After the entire campus landscape system is basically planned, use a physical simulation software set to optimize the layout of the building groups so as to form the best outdoor micro-climate. (3) At the late architectural design stage, the walking space around the buildings is optimized by making full use of greening, shelf, building components to form large shading area.

\section{CONCLUSION}

With the Green Action, the outdoor physical environment design of a green campus can be achieved with fruitful results. However, based on the literature review in this paper, it shows that there are shortcomings in the current practices on the design of the physical environment of the green campus. This study has developed a design method in which the design of the green campus outdoor physical environment starts from the planning stage. It then advances the design of the campus outdoor environment to the planning level. The green campus, suitable for certain climatic characteristics and geographical conditions, is a low-cost design strategy for a campus outdoor physical environment.

\section{ACKNOWLEDGMENT}

This subject is supported by National Natural Science Foundation of China National Natural Science Foundation of China of Science Fund for youth: Study on the quantitative control of the design parameters and the coordination mechanism of the key variables in the near zero energy consumption residential buildings in the cold area ( NSFC Grant No. 60173046).

\section{REFERENCES}

[1] T. Fang, "The research and practice on the composition of the green campus of the University: take the new campus of Shandong Jianzhu University construction as an example,” Jinan: Shandong Jianzhu University, 2009.

[2] China Green Building Council, Evaluation Standard for Green Campus (CSUS/GBC 04-2013), unpublished.

[3] Ministry of Housing and Urban-Rural Development of the People's Republic of China, Assessment standard for green building, GB/T50378-2014, Beijing: China Architecture and Building press, 2015.

[4] H W. Tan, "Thoughts over the development of green campus in China”, World Environment, vol. 5, pp. 30-34, May 2016.

[5] P. Liu, H. Mao and J Y. Liu, "Study on and practice of planning and design for green campus: a case study on southern university of science and technology of china”, Eco-city and Green Building, vol. 1, pp. 7075, January 2012.

[6] T M. Shi and S. Li, “The constuction strategy of green campus taking the constuction of Shenyang Jianzhu University for example”, Engineering Mechanics, Vol.29 Suppl II, pp. 9-14, December 2012.

[7] W W. Zhou, "Practice of green campus in hot summer and cold winter zone-Taking the new campus project of Changzhou Higher Vocational and Technical School in Jiangsu Province as an example”, Construction Science and Technology,vol. 12, pp. 57-59, December 2013.

[8] W L. Liu and X. Ju, "The strategy research of the green campus development and construction”,Journal of Shenyang Jianzhu University(Social Science),vol. 16 No.3, pp. 235-239, June 2014.

[9] Y W. Wang, "Study on problem in energy saving and emission reduction about green campus in China”, Eco-city and Green Building, vol.3, pp.24-27, June 2010.

[10] C. Chen, X Y. Yuan and Y L. Wang, "The low-cost implementation of green and low-carbon notions in the humanistic campus: Shenzhen Lihu middle school ", New Architecture, vol. 4, pp. 64-68, April 2013.

[11] Y. Hao, L. Cao and Y. Li, "Design of low impact in green campus landscape”, Construction Science and Technology, vol. 9, pp. 114-117, September 2014.

[12] C J. Wang, "The idea and practice of green campus construction in Shandong Jianzhu University”, Construction and Architecture, vol. 22, pp. 30-31, November 2014.

[13] B. Hu and L. Zeng, "To create the education-oriented green campus for the secondary school: Meixihu middle school in Changsha”, Urbanism and Architecture, vol. 2, pp. 43-45, December 2012.

[14] T H. Zhou, "Study on green campus environment assessment system based on ecological footprint method”, Changsha: Hunan University, 2012.

[15] G H. Tian, W. Liu, Z K. Miao and J Xiang, "Strategy study on the energy-conservation reconstruction for green campus based on the green campus standard”, Building Energy Efficiency, vol. 1, pp. 85-88, January 2014.

[16] J J. Yang, L Y. Shen, J Y. Zhou and P F. Zhang, “Comparativa study on green campus evaluation system at home and abroad ”, Construction Economy, vol. 2, pp. 91-94, February 2016.

[17] W H. Guo and X. Liu, "Planning design strategy and practice research on green University campus ”, Building Energy Efficiency, vol. 1, pp. 70-80, January 2016.

[18] H D. Li, "Organization of landscape elements based on CFD and Evaluation Standard for Green Campus”, Building Energy Efficiency, vol. 9, pp. 68-92, September 2014. 
[19] B X. Li, J Y. Zhang and J. Liu, "Research and practice on green campus design method based on wind and water environment optimization", Building Energy Efficiency, vol. 1, pp. 56-61, January 2016.

[20] L M. Xu and W. Wang, "A review of the research on the appropriate technical system of low cost green campus”, Journal of Green Science and Technology, vol. 10, pp.229-232, October 2013.

[21] W. Wang, "Elementary study on the planning to construct green campus”, Chinese and Overseas Architecture, vol.12, pp. 93-94, December 2014.

[22] Y. Zhang and Z G. Chen, "Study on the strategy of green campus construction in China's severe cold climate region”, Urbanism and Architecture, vol. 19, pp. 119-121, June 2015.

[23] Y L. Wang, X Y. Yuan, and C. Chen, "Integration of tradition and green technology in campus building: a case study on green campus design of Lihu middle school in Nanshan District, Shenzhen”, Eco-city and Green Building, vol.1, pp. 56-63, January 2012.

[24] H. Tai, "The problems research of green campus constrution- Tsinghua University as an example”, Changchun: Northeast Normal University, 2014.

[25] X F. Liao, M. Liu, X Y. Gao, X D. Wang and Y Q, Zhong, "Comparative analysis of environment items in global green campus evaluation systems” Journal of Civil, Architectural and Environmental Engineering, vol. 38, pp. 204-208, July2016.

[26] L Y. Xu, Y K. Zhang and H. Zhang, "Environment analysis of the planning and architecture design for new campus of Shijiazhuang Jingji University”, Building Energy Efficiency, vol. 7, pp. 67-71,July 2014.

[27] B X. Li, J. Liu, J Y. Zhang, J H. Liu and X D. Li, "Research and practice on green school design method based on climate adaptability", Green Building, vol. 5, pp. 61-64, May 2015.

[28] H F. Tian and J. Lin, "The way and practice of building green campus", Construction science and technology, vol. 24, pp. 31-35, December 2015.

[29] F. Gao and W. Liu, "Study on development strategy of green campus: Case study on new campus of Tianjin University”, Green Building, vol. 2, pp. 62-64, February 2016.

[30] F Gao, H Z. Zhou, W F. Wang and H. Yan. "Study of the design strategies of green campus in northern Area-New campus of Tianjin University”, Journal of Tianjin University(Social Sciences), vol. 5, pp. 412-417, May 2015.

[31] F. Jiang, "Green campus design practice of simulation technology under physical environment: a case of the planning concept design project of east campus in the Beijing People's University of China”, Huazhong Architecture , vol. 3, pp. 112-116, March 2015.

[32] Y. Zhou, B F. Zhu and J. Ge, "Sino-American comparison and improvement study on the suitability of evaluation standard for green campus”,[J]. Architectural Journal, vol. 14 S1, pp. 150-154, January 2016.

[33] Z H. Li, C. Peng and L. Ding, "Present Situation and Countermeasures for Building Green Campus of Hubei Institute for Nationalities", China Educational Technology and Equipment, vol. 4, pp. 126-128, April 2014.

[34] Y H. Cao, "Energy saving design of green campus building”. Shanghai: Fudan University, 2013.

[35] Z. Guo, "Study on the design strategy of green campus", Shanghai: Shanghai Jiaotong University,2014.

[36] S H. Jia, "Research on green campus policy in Sweden”, Beijing: Capital Normal University, 2014.

[37] Y T. Li, M Y. Bai, X. Wang, and J P. Chen, "The practice of green campus planning and construction: a case study of the construction of the new campus of Higher Vocational and technical school in Jiangsu province", Construction Science and Technology, vol. 24, pp. 16-19, December 2015.

[38] Y T. Li and J Y. Liu, "Design strategy and case analysis of green campus”, Construction Science and Technology, vol. 24, pp. 20-22, December 2015.

[39] X R. Xiao and W H. Guo, "On evaluation index of green campus planning in Higher Vocational College", Chinese and Overseas Architecture, vol. 3, pp. 88-92, March 2016.
[40] X. Yang and Y X. Chen, "Thinking and practice on construction of green campuses in primary and middle schools”, Housing Science, vol. 4, pp. 18-22, April 2016.

[41] H W. Tan, "Challenges and opportunities of green campus", Construction Science and Technology, vol. 12, pp. 13-15, December 2016.

[42] H F. Tian, "Green campus practice of new countryside in hot summer and cold winter zone", Construction Science and Technology, vol. 12, pp. 22-24, December 2016.

[43] L Q. Gao, L. Liang and Z. Jun, "The Green-Campus planning of the mountain building for the terrain in Hebei area: A case study of Shijiazhuang Tiedao University Sifang College”, Huazhong Architecture, vol. 10, pp. 115-118, October 2016.

[44] G J. Song and J. Wang, "Design of green energy saving campus based on low-carbon building application: a case study of the Yangzijin Campus of Yangzhou University”, Huazhong Architecture, vol. 9, pp. 121-124, September 2015.

[45] B F. Zhu, "Between China and America combined with case evaluation and optimization research”, Hangzhou: Zhejiang University, 2016. 